A well defined suture along the thoracic meson; at $12: 46$ P. M., with great suddenness, thorax parted along the meson, and the head and thorax shot out, as it were. In $5^{\circ}$ seconds the wings and greater part of body were out, while in $j$ seconds more the fly was resting on the surface of the water completely excluded. At $12: 48$ (2 minutes), the pupal skin was discarded and thrown aside, and the adult floated off. During the interval of time between the exclusion of the wings and the discarding of the pupal skin, the fly was simply resting on the surface of the water, the tip of the abdomen being supported by the cast skin. After floating a short distance, the body rapidly drying, it flew several yards and alighted on the water, and at $\mathbf{1 2 : 5 0}$ P. $\mathbf{3 r}$. it again flew a short distance to the shady side of a $\log$ in the water. Took flight at $12: 56 \mathrm{P}$. $\mathrm{x}$.

In another case exclusion occupied six minutes, and the fly fiew away eight minutes afterwards. The pupa was at first cruising over the water, the half excluded wings acting as sails, until it came to rest against a half submerged log, upon which the adult crawled as soon as free from the pupal skin.

Pupae and adults were present until April 28.

\title{
A Supposed Cynipid Gall from the Roots of Goldenrod (Solidajo).
}

Desc. Gall. - Flattened, clustered, fleshy, bud-like, root-galls; dark olive green, tinged with garnet; soft, flabby to touch; multicellular, the larval cells long; taste neutral, like parsley; tuber-like when large. Diameter : 4-r r mm. (single galls.) Locality: Ridgeley, W. Virginia.

History. - Occasional; larvae and parasitic pupae present; no adults obtained; 22 Aug. 1903.

A. Arsène Girault, Paris, Texils. 

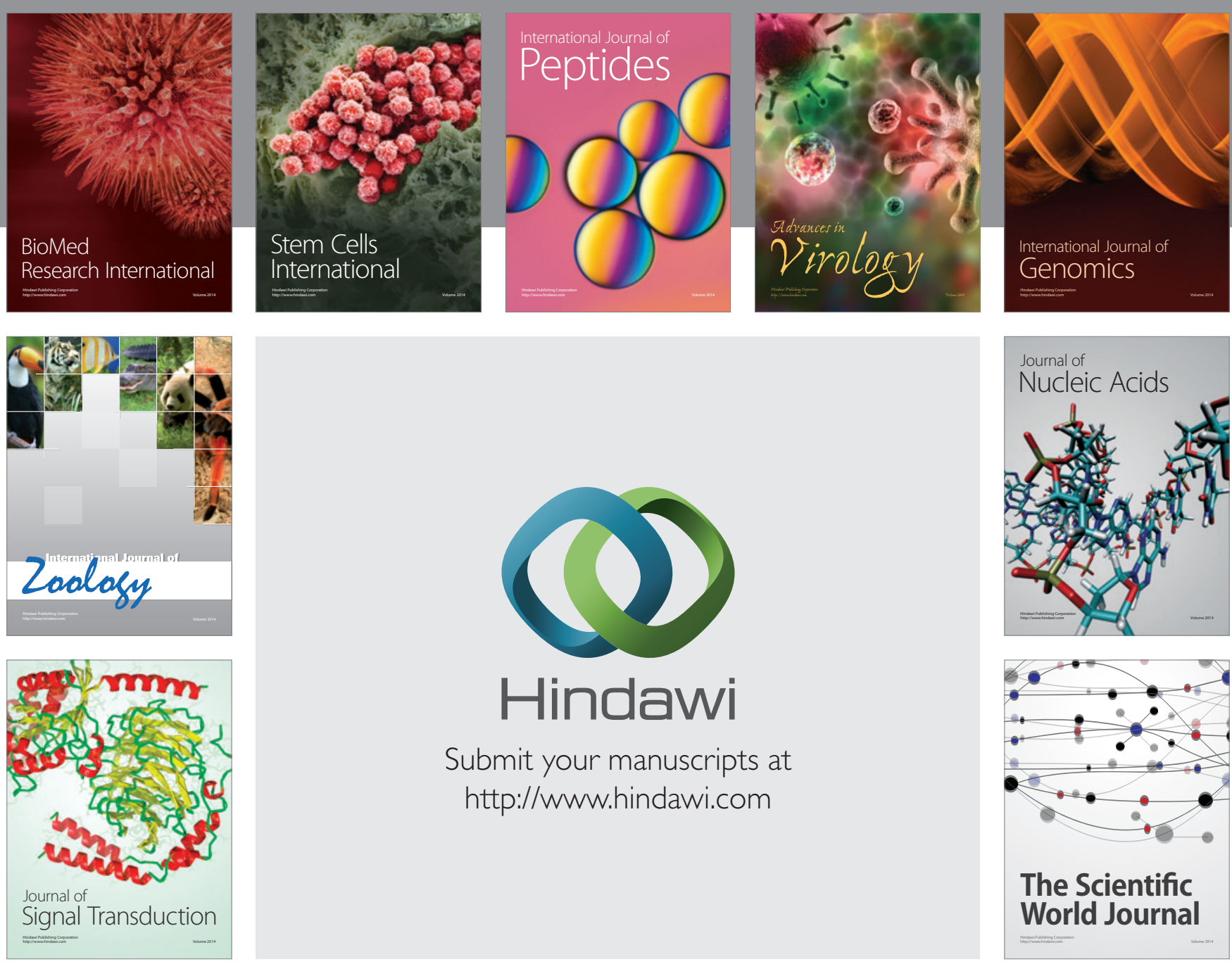

Submit your manuscripts at

http://www.hindawi.com
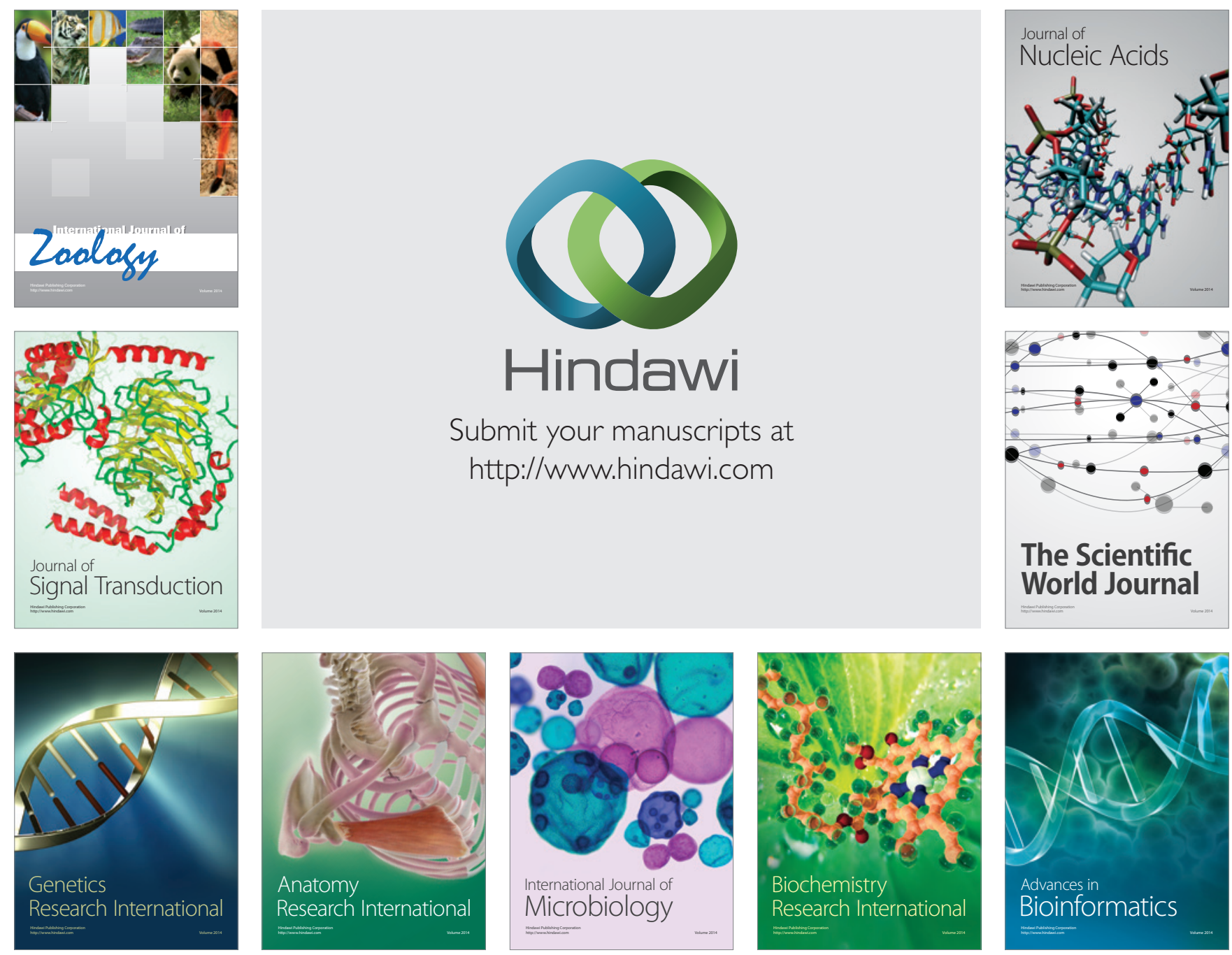

The Scientific World Journal
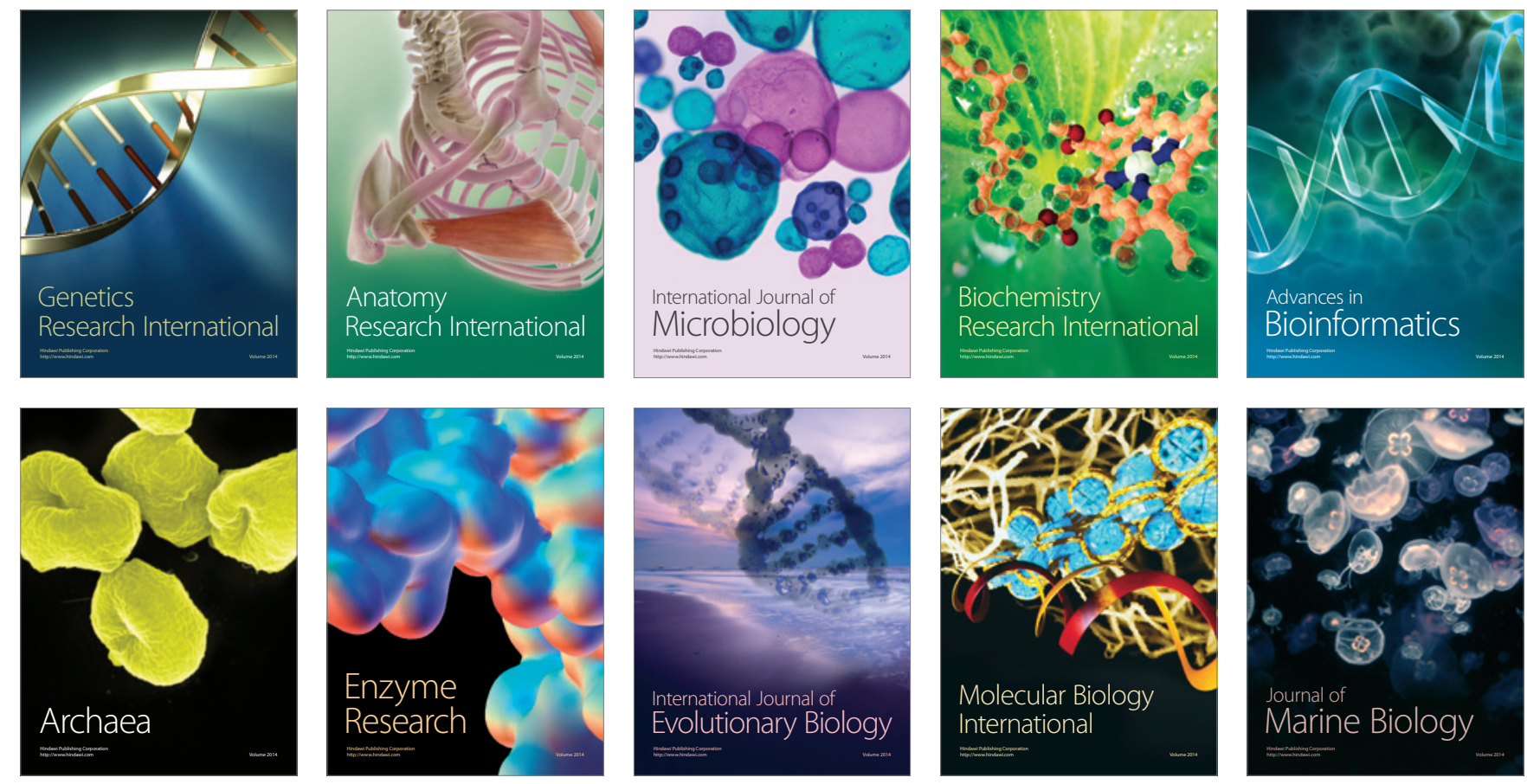